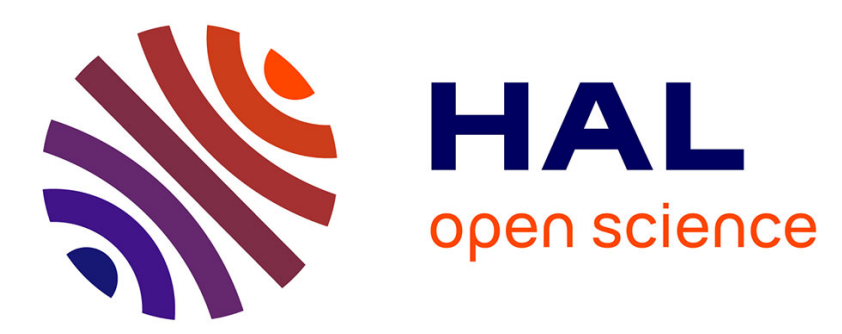

\title{
History of the opposition between psychogenesis and organogenesis in classic psychiatry: Part 1 \\ Yorgos Dimitriadis
}

\section{To cite this version:}

Yorgos Dimitriadis. History of the opposition between psychogenesis and organogenesis in classic psychiatry: Part 1. History of Psychiatry, 2020, 31 (2), pp.208-216. 10.1177/0957154X20904036 . hal-02553097

\section{HAL Id: hal-02553097 \\ https://hal-univ-paris.archives-ouvertes.fr/hal-02553097}

Submitted on 24 Apr 2020

HAL is a multi-disciplinary open access archive for the deposit and dissemination of scientific research documents, whether they are published or not. The documents may come from teaching and research institutions in France or abroad, or from public or private research centers.
L'archive ouverte pluridisciplinaire HAL, est destinée au dépôt et à la diffusion de documents scientifiques de niveau recherche, publiés ou non, émanant des établissements d'enseignement et de recherche français ou étrangers, des laboratoires publics ou privés. 
History of the opposition between psychogenesis and organogenesis in classic psychiatry: Part 1

Yorgos Dimitriadis

Université de Paris, France

Edited by

Professor Tom Dening

Corresponding author:

Yorgos Dimitriadis, chez CRPMS F-75013, Université de Paris, 5 rue Thomas Mann, 75013 Paris, France.

Email: dimitriadisyorgos@gmail.com 


\begin{abstract}
The question of causation in psychiatry is one of the oldest and most difficult in this field. This paper is the first of two published in this journal. First, it traces the development of psychogenic and organogenic views of mental disorders from Pinel until the early twentieth century. This includes the debate as to how a disturbance of function might create a lesion even without a visible pathological trace. The second part of the paper discusses in detail the controversy between functional and organic causes of mental disease. These concepts evolved taking into account psychological factors and also the response of the uninjured parts of the nervous system to trauma of various kinds.
\end{abstract}

\title{
Keywords
}

History, functional, organogenesis, psychiatry, psychogenesis, psychosomatic

The question of psychogenesis and organogenesis is among the earliest controversies in psychiatry and, according to Henri Ey (1950), its most difficult issue to resolve. In the early nineteenth century, this debate regarding mental diseases was expressed through the opposition between functional and organic disorders. This applied not only to mental diseases but also to somatic symptoms, such as functional pain vs. organic pain. The terms psychogenesis and organogenesis are found in the psychiatric vocabulary around the end of the nineteenth century, but these terms were never used exclusively. For example, other words like endogenous, constitutional, cryptogenetic, somatogenic, physiogenesis, hereditary, idiopathic, autonomous or psychotic were applied to 'organic' disorders and terms like exogenous, reactive, psychogenic, neurotic or sociogenic referred to 'psychogenic' disorders. As might be expected, this created considerable confusion. For example, Auguste Morel's degeneration theory flirted with both the terms 'psychogenic' and 'endogenous', and Kraepelin believed paranoia, in its querulous form, to be at the same time psychogenic and endogenous.

\section{A brief history of the debate between psychogenesis and organogenesis}

Georges Lanteri-Laura (1998) divided modern psychiatry into three periods, or paradigms (inspired by Kuhn's notion of paradigms). These were, respectively: 'mental alienation', 'mental diseases', and 'psychopathological structures'. The relationship between psychogenic 
and organic causation varied during these periods and some of the key ideas from each of these period paradigms are discussed in the following sections.

\section{The period paradigm of 'mental alienation'}

This term referred to mental states that were believed to necessitate the internment of a patient. During this period, mental alienation was conceived as a unitary phenomenon (Lanteri-Laura, 1998). Pinel was probably the first person to consider mental alienation to be a disease in the sense of organic diseases, a disorder of the intellectual functions, i.e. of the superior functions of the nervous system. Thus, he chose to classify it among the neuroses, that is to say in the category of diseases of the nervous system without inflammation or structural lesions, as opposed to phlegmasia, haemorrhages, organic lesions, or fever. Pinel considered the causes of mental alienation (apart from lesions) to be diseases of other organs (sympathetic causes), heredity, and moral causes. Moral causes, which he believed to be the most frequent and important, have an effect on the state of the viscera and on higher functions, and subsequently on the brain via the sympathetic pathway. Additionally, the causes were not regarded as being specific to a particular type of alienation, and various types could occur in the same individual, aside from congenital idiocy.

Therefore, even if the question was not fully clear, Pinel began distinguishing between symptomatic insanity and idiopathic or essential insanity. Pinel's principles were adopted by his successors, Esquirol and Georget. Esquirol (1998) contributed by distinguishing two categories of causes: predisposing factors and excitation. At the time, the school of thought originated by Pinel was opposed by the 'anatomists' (Parchappe, Calmeil, etc.) who, though unable clearly to formulate a mechanism, adopted a monistic point of view towards insanity. This was not quite the same as phrenology, Gall's theory of localization, which suggested that if a cortical region's hypertrophy results from a mental disruption, then irritation of the same area by a morbid process (inflammation or organic lesion) can produce the same result. The anatomo-pathological school of Gall led to an intense search for cerebral lesions as possible causes of mental alienation.

In the end, the views of Pinel's and his school prevailed, thus establishing the terms for the debate whose history this paper addresses. As Jacques Postel observed in the introduction to a modern edition of Georget's De la Folie (1999), this was the beginning of the distinction between psychiatry and neuropsychiatry. 
Georget pointed out the distinction between symptomatic diseases, which stem from a known organic cause, and idiopathic disorders, whose precise origin is unknown but evidently result from purely functional disruptions and which correspond to insanity in the strict sense. He was the first to suggest an aetiological division of mental disorders: ${ }^{1}$ moral causes in the case of insanity and physical ones in the case of acute delusion, the only 'sympathetic' disorder, i.e. subsequent to the disruption of other organs. According to Georget, in the case of insanity, the problem is entirely in the brain, which thus becomes the 'diseased organ'.

Georget observed that the affection of the brain in mental alienation was idiopathic, of unknown nature; and he implied that the progression of mental alienation has its own course, independent from its precipitating causes. Georget saw this as a fundamental difference from symptomatic disorders, whose evolution is always dependent on the causes that produce them. Predisposing factors, especially heredity, had significant effects upon mental alienation.

However, Georget disputed the theory of his predecessors (and teachers), Pinel and Esquirol, according to whom passions had their effects on the brain via the viscera. In contrast, according to Georget, the causes of both the passions and insanity should be sought in the brain, the organ of reason. 'After having previously proven that the brain is the organ of intelligence and passions, I believe it is pointless to attempt here to prove that moral affections which can bring about mental alienation have a direct effect on it' (Georget, 1999: 78). For Georget, the term 'cerebral' did not have the restrictive, 'organogenetic' meaning that it has been given today, but a broader one that prevented him from being caught in the organogenesis/psychogenesis dilemma:

The extension of that meaning becomes clear more specifically with regard to the moral treatment which to him is the only 'true direct cerebral treatment'. Hence, 'cerebral' genuinely encompasses the physical and the moral, the physiological and the psychological. But ... this monism is only possible and methodologically valid because the psychiatric field of psychosis has been carefully defined in comparison to the neuropsychiatric field of frenzy and symptomatic mental disorders. (Postel, 2007: 130)

The period paradigm of 'mental diseases' 
For Lanteri-Laura (1998), this period spanned from 1854 to 1926. It was characterized by a search for a more specific classification of the signs, evolution and aetiology of mental disorders. The various mental diseases were necessarily plural and could not be reduced to a single entity. Their classification required a system of specific signs, at least in part organized into a semiologic structure, allowing for the characterization of morbid types which cannot be reduced one to another. Each mental disease should have its own specific group of signs, its own particular evolution and, at least in some cases, a definite aetiology.

As we have previously seen, for Pinel, the causes of alienation were vague, depending on a range of physical, physiological, hereditary or moral factors (see Jeannerod, 1996: 150 1). After Bayle's (1822) anatomopathological work on general paralysis, the need for a characteristic lesion became necessary for the classification of diseases. However, aside from general paralysis, no microscopic lesions could be found. This led to the development of a concept of dyanamic, as opposed to anatomical, lesion. For example, this was described by Moreau de Tours (see Jeannerod, 1996: 153) in the following terms: 'of a material and molecular lesion, however elusive ... as can be for example the changes that occur in the inner structure of a rope moved in a vibratory motion'.

However, after the identification of general paralysis - a natural disease with a specific cause and relatively predictable course - research turned towards the detailed description of the various mental diseases. This work, led notably by J-P Falret (see Lanteri-Laura, 1998), focused not only on their similarities but also on their differences, in terms of effects on function, their various phases and oscillations, and variations within each condition. Falret's circular insanity and his rival Baillarger's dual-form insanity (which later became periodic insanity then manic-depressive insanity in Kraepelin's work) were the normative types representative of this period. Lasègue's persecutory delusion with progressive evolution and Jules Falret's delusion of doubt with dread of touch are other examples of the level of interest in both the course and content of mental diseases.

Griesinger (1865), the father of German psychiatry and author of the first treatise of psychiatry in 1845 , was perhaps the first to consider mental diseases in their evolution. However, he still considered the different types of insanity to be phases of the same process, from initial phrenalgia (term borrowed from Guislain) to terminal, end-stage dementia, a process that at each stage can either fixate itself or regress. As observed by Bercherie (1980: 62), Griesinger was the origin of ideas later developed by Blondel, Jaspers and Guiraud. We can also find, in Herbart's work, influences that led to Freud's concepts of the ego, of repression and of psychosis. We quote Bercherie with regard to this particular point: 
The cerebral disease brings about dispositions and penchants that become the starting point of emotions ... it produces psychical neo-formations ... . In the beginning, the ego feels the effects of these phenomena with an obscure feeling of anxiety, of moral suffering ... . In any case, the new mental state will progressively engender matching representations, false judgements (idées fixes) which the patient is unable to rectify. (Bercherie, 1980: 62 et seq.)

In France, during this period, Morel (see Bercherie, 1980: 93) developed his 'degeneration' theory which is more of a synthetic attempt than an analytical one. Morel was among the first to emphasize how organic factors, for example progressive heredity throughout successive generations, might interact with harmful experiences during infancy, thus, as observed by Bercherie (1980), indirectly initiating psychodynamic psychiatry.

Towards the end of the nineteenth century, there was a second attempt in France (after Georget) to separate neurology and psychiatry. According to the sociologist Alain Ehrenberg, this divergence began with Charcot's work on hysteria, before being achieved with Bernheim and Freud:

Charcot explains that the discriminating sign of the hysterical person is his ability to be influenced through hypnosis which produces a reaction of a physiological nature - not a psychological one .... Disqualifying that notion gives birth to psychopathology on the one hand, and defines neurology's field of action on the other ... . This idea is considered by Bernheim ... who establishes that anyone may be hypnotized, not only the hysterical person, and that therefore Charcot is mistaken. (Ehrenberg, 2004: 135)

Bernheim pointed out that some hypnotized subjects will only follow suggestions that they find to be agreeable or inconsequential. Hence, if not everyone is susceptible to any kind of suggestion, there must be something in the subject that accepts or refuses it. Ehrenberg suggests that this shows the emergence of another type of functionality that no longer requires an organic basis to justify itself and that is autonomous with regard to the lesion. This separation allows for another agency: the psyche. Following this, Freud conceived a novel means of treatment based upon the psychical content. Thus, subjectivity became a matter of study. 
During the same period in Germany, Kraepelin, influenced by the theory of degeneration, took an organic view of mental illnesses, and he considered essential psychoses to be endogenous. Kraepelin suggested a potential mechanism of biochemical selfintoxication associated with the development of sexuality which could be responsible for the deterioration of cortical cells (De Waelhens, 1980: 10). It has been suggested that this enabled him to ignore the potential importance of social factors; in other words, that his views 'support, against the alienated individual, a society untarnished by any suspicion of responsibility towards said alienation' (Postel, 1997: 16). Eugène Bleuler, despite his psychopathological orientation influenced by Freudian theory, classified Assoziationslockerung (usually translated as 'dissociation of associations') as the first primary symptom of organic origin causing disorders associated with schizophrenia. According to De Waelhens (1980: 17):

Bleuler, though he does not disown organicism - he even maintains that only an organicist explanation, if it were to prevail, could turn out to be fully satisfactory -, believes nevertheless that a psychogenetic origin of the disease should not be discarded, even though he personally does not share that opinion.

Bleuler (see Bercherie, 1980: 200-1) and also Jung (1907/2001) suggested that in many cases of dementia praecox there is a fixation of affective complexes (an idea already expressed by Griesinger), a fixation that occurs through a toxin (an idea already present in Kraepelin) which operates before the fixation itself in order to bring about the complexes (Bleuler's opinion; see Bercherie, 1980: 200-1), or which is initially produced by the complex whose causes are psychological and then sets the complex (Jung's preferred view). Particularly in the ideas of Jung, this is probably the first evidence of a theory of a psychosomatic affection of the brain in schizophrenia (see Dimitriadis, 2018).

\section{The period paradigm of 'psychopathological structures'}

The notion of specific mental diseases was challenged, however, by the epidemic of lethargic encephalitis that spread throughout Europe between 1917 and 1925. This disease caused a wide range of clinical symptoms, often resembling other mental disorders. Thus the same disease process could produce different clinical pictures, but also attempts at cerebral 
localization seemed of limited value for psychiatry, as discussed by Lanteri-Laura (1998: $135)$.

In the early twentieth century, the introduction of a range of physical treatments strengthened the organicist conception of insanity. These included malaria inoculation (and later, penicillin) for syphilis, Sakel's treatment (insulin) [1932], Cardiazol [1935], electroshock therapy [1938], psychosurgery through prefrontal lobotomy [1935], and after 1950, neuroleptics, antidepressants and mood regulating drugs (see Bercherie, 2005: 86).

Alongside this, however, the 1920s saw the development of more 'dynamic' theories under the influence of the Gestalt theory and of structuralism, and especially Gelb and Goldstein's (Goldstein, 1983) neurological globalism (which rejected localizing conceptions and argued that the nervous system should be regarded im Ganzheit, i.e. in its totality). Lanteri-Laura's classification names this as the period of the 'psychopathological structures' in which the meticulous description of the signs of the various diseases is no longer as important. Instead, what matters is the identification of the psychopathological element specific to each clinical entity.

An early example is provided by the studies of Monakow and Mourgue (1928), midway between neurology and psychiatry (discussed below). Paul Guiraud (1950) maintained that the disorders causing mental diseases were fundamentally disorders of the primordial psychic activity, i.e. of the global psychical experience (éprouvé psychique global), the psychological aspect of the organic vital functions, mainly diencephalic in origin (see Follin, 1993). Eugène Minkowski (1968) described the loss of vital contact with reality (the predominance of autism over Bleuler's dissociation in schizophrenics as well), and Ludwig Binswanger (2000) discussed flight of ideas in manic subjects. Henri Ey (2006) proposed an organodynamic theory, influenced by the work of John Hughlings Jackson (see Guiraud, 1950: 140-63), a British doctor who during the 1880s was suggesting a layered conception of the nervous system inspired by Spencer's evolutionary theory. Ey posited that the global de-structuring of the nervous system, of the conscience in the case of acute psychoses, and of the personality in the case of the chronic aspects of the mental pathology (psychotic, neurotic, deficient), constitutes the psychiatric pathology strictly speaking. Due to its global character, this destructuring liberates the inferior automatic centres and thereby fundamentally alters the freedom of the person. According to Ey, this concept is the opposite of mechanistic interpretations, such as de Clérambault's theory of psychic automatism caused by local irritation of the brain ('épine irritative'). In addition, in Ey's theory psychogenesis found itself confined to normality. 


\section{The opposition between functional and organic}

\section{Functional disorders}

Probably the first person to speak of functional disorders was the Scottish physician William Cullen in 1776 (Minkowski, 1935). According to Cullen (see Minkowski, 1935), these were diseases which were not caused by organic alterations of cells or of nerve fibres but by anomalies in their functioning in various parts of the nervous system without any precise anatomical corollary - anomalies of an erratic and fleeting character, and in theory reversible. These anomalies were initially considered mainly from a pathophysiological point of view. In France, the term 'functional' was not used in medical vocabulary until about 1830 (see Starobinski, 1999: 393). The term 'functionalism' (a word which in 1866 Louis Fleury opposed to 'organicism'; Starobinski, 1999: 393) was also sometimes used, though it did not persist for long.

At the beginning of the nineteenth century, Broussais (1828) formulated his physiological theory of 'irritation and insanity'. He believed that the organism's reaction to stimulating factors was more important in determining the characteristics of the disease than its specific cause. Thus, autopsy lesions may arise as the consequence of functional disorders, chronic irritation or sub-inflammation of the brain. Claude Bernard (see Grmek, 1997) also posited that the lesion is the consequence of the disease and not its root, but this does not preclude the possibility that this lesion may itself become a morbid source of other subsequent symptoms. We have already mentioned that Pinel, similarly, believed that passions affect the viscera which in turn affect the brain via the sympathetic pathway. Indeed, this idea also resembles aspects of the doctrine of Hippocrates (the 'black bile' and the 'wandering womb').

Neurasthenia was classified among these rather neurological diseases: it was described by Beard in 1880 (see Minkowski, 1935) as a mainly somatic disease, with alterations of the blood, internal organs, and the sympathetic nervous system, although it also came with psychical disorders such as feebleness of will, character alteration, irritability etc. In the same group could obviously be found hysteria, considered to be a reflex neurosis, i.e. a disorder originating from the viscera, and more specifically from the genital organs, according to Hippocrates's theory which was able to maintain itself for so long. We have also seen that the term 'functional' was already present in Pinel's followers, in particular Georget, who considered it to be a principle of mental alienation. 
It was not until the second half of the nineteenth century that the psychical component in the so-called functional diseases was pointed out in a more specific way. This began with the study of hysteria by Briquet (1859), who imputed an essential importance to psychical and moral factors that deeply affect the human personality while admitting that there are specific regions of the brain which serve as the basis for various disorders. The work of the Nancy school (Liébault, Bernheim) on hypnosis and suggestion (see Minkowski, 1935) impacted on the evolution of these ideas, establishing the effects of psychical factors on the nervous system, both somatic and visceral.

We have previously mentioned Charcot (1971) and his school. Charcot stressed the importance of affective factors that may strike the imagination or the feelings, with regard to the preparation, triggering and causal determination of neurotic disorders. In his synthetic theory of organic and functional disorders, the similarity between neurological and hysterical symptoms had implications for pathologists, since they could infer the location of the dynamic lesion from that of a corresponding organic lesion. Babinski, previously the head of Charcot's clinic, went further and reduced hysteria to pithiatism, that is to phenomena which can be triggered and eliminated through suggestion. This had the effect, as observed by Ehrenberg (2004), of sealing off neurology from the unobjectifiable. His contribution, according to Ehrenberg (2004: 137), is 'having established a boundary separating the neurological from the pathological, thus questioning our ability to understand mental states from cerebral ones'. Babinski thereby opposed Charcot who wanted, through the anatomoclinical method and based on objective grounds (Ehrenberg, 2004: 137), to establish a physical semiology of hysteria (stigmata, for instance).

A further stimulus to the study of functional disorders and their classification came from the observation and the analysis of disorders occurring in the wake of accidents (Minkowski, 1935). The concepts of hystero-trauma by Charcot, of sinistrosis (sinistrose) by Brissau, of 'appetition' neurosis, of annuity, etc. were introduced. Oppenheim, when speaking of neuroses, and more particularly of traumatic neuroses, emphasized the presence of heightened affective irritability and of an increased influence of emotional factors on motor, sensitive, and even more importantly, on vasomotor and secretory innervations, that is to say on the vegetative nervous system. Similarly, Babinski and Froment created the concept of secondary neuropathic disorders (see Minkowski, 1935), resulting from trauma, without any known organic lesion, resistant to counter-suggestion and seemingly connected to affections of the sympathetic system. 
Freud definitively changed hysteria's status, from being a neurosis, of organic cause but reversible, to neuropsychosis, resulting from psychological causes. Initially, influenced by Charcot and the school of Nancy, he considered the causes to be related to suggestion. In a second phase, he believed hysteria to result from the effects of the recollection of childhood traumatic episodes. His final view, when he 'ceases believing in his neurotica' (see Le Gauffey, 1992a, 1992b), was that the predominant role was not played by childhood traumatic events but by fantasies. Likewise, Janet (see Le Gauffey, 1992a, 1992b) distinguished from Beard's neurasthenia those cases in which psychological factors play a predominant role and gathered them under the term psychasthenia. Janet also suggested that in hysteria there was a reduction of psychological tension, with dissociation and a diminished field of consciousness.

\section{Organic disorders}

According to Jacques Vié (1934), in the first quarter of the twentieth century, the organicity of a nervous illness was determined by the following three criteria:
a) Presence of a noticeable lesion during autopsy;
b) Invariability of the symptoms in relation to the fixity of the lesions;
c) Impossibility of reproducing said symptoms through volition.

With the evolution of medical research, these criteria gradually changed until they became, at the time of Vié's paper in 1934: an anatomo-physiological disruption (transitory or definitive lesion) affecting a specific segment or system of the neuraxis; the presence of symptoms consistently related to the anatomo-physiological disorder; and a tangible aetiological factor (physical, chemical, infectious) occasionally confirmed by the results of treatment. Vié observed that the term functional was used for two very distinct categories of events, either related to morbid processes, or else in continuity with normal functions:

The first ones ... are clearly pathological, related to the organ's affection, i.e. to the aetiological agent. ... It is neither a matter of 'paranormal' nor of 'juxta-normal' but one of pure morbidity. On the other side of these morbid functional disorders of indisputable organic nature, the functional ... persists with the physiological, gathers the modifications the morbid process brings to the usual functions of the organs: these 
react, adapt, or to use a word free of any kind of finalism, behave as they can in front of the new situation forced upon them. (p. 68)

According to Vié, functional disorders extend beyond the boundaries of organic pathology. They arise from the relation between the organ and the object of its function (food for the digestive tract, atmospheric factors for the respiratory system, etc.). The formulation that 'they are produced in the relation between the organ and the object of its function' (p. 68) is a sophisticated statement regarding functional disorders, in some respects more elaborate than some contemporary theories on mental disorders proposed e.g. by neuroscientific reductionism.

Under the influence of von Monakow, a Swiss-Russian doctor based in Zurich and one of the forefathers of the theory of form in neurology and in psychopathology, the relation between organic and functional blossomed anew (Minkowski, 1935: 10 et. seq.). With regard to neurological disorders, he placed less emphasis on the nature and extent of damage to the nervous system, but more upon what remains, and how the preserved parts of the damaged nervous system (and through that the whole organism) carry on functioning under the conditions of the said damage. Hence, the disorders become organo-functional, potentially producing psychogenic or psycho-functional elements in continuity with normal psychical reactions which, for their part, will make the clinical picture more complicated and more variable.

Von Monakow (see Minkowski, 1935: 17) regarded neuroses as prolonged affective reactions, generally psychical ones, arising from the personality against intense assaults. These assaults, often repetitive and cumulated, target the personality's instinctive sphere, i.e. its most vital interests, and can affect the subject's sexual life as well as his physical, psychical or moral integrity by way of trauma, disease, depravation, outrage to one's prestige and honour, etc. According to this physiopathological viewpoint, there probably needs to be an underlying constitutional disposition that should probably be conceived as a hereditary deficiency, either congenital or acquired very early in life, of various systems, such as endocrine and autonomic function, and the integrity of the blood-brain barrier.

Von Monakow and Mourgue (1928), in their work Introduction biologique à l'étude de la neurologie et de la psychopathologie, considered that even at the level of the neurological lesion there is always a tendency towards rebuilding and restitution. Each time there is disintegration, there will always be a tendency towards reintegration (for a summary of this theory, see Guiraud, 1950: 164-82). Their views differed from those of Hughlings Jackson, 
who has proposed that disintegration was followed by a passive liberation of the inferior centres (phylogenetically), whereas von Monakow and Mourgue were suggesting a more active process aimed at restoring impaired function. Jean Oury (1989: 56) described this as follows:

... in every disaster, every lesion, every organic aggression, there is a self-regulation mechanism that is triggered. But if this term is to be used, we hit a dead-end! Consequently, they borrow another term from the Stoics, 'syneidisis'. To wit, that when something goes wrong, an extraordinary energy makes its appearance attempting to integrate, to restore a sufficient level necessary to make things function. And sometimes, that level can even be surpassed.

\section{Conclusion}

This paper has traced the history of psychogenesis and organogenesis as causes of mental disorder, and described the development of ideas about functional versus organic disorders. An accompanying paper (Part 2) takes this account further, including an analysis of ideas about psychogenesis and other concepts such as endogenous, exogenous and reactional.

[Part 2 will be published in History of Psychiatry 31(3)]

\section{Funding}

This research received no specific grant from any funding agency in the public, commercial or not-for-profit sectors.

\section{Note}

1. According to Jacques Postel (2007: 227), Georget was a rigorous reader of English authors who distinguished 'delirious states' from 'delusions', and of German ones who distinguished 'Delirium' from 'Wahn'.

\section{References}

Bayle A-L-J (1822) Recherches sur les maladies mentales. MD thesis, Faculté de Médecine de Paris, France (Thesis no. 247, Imp. Didot le Jeune).

Bercherie P (1980) Les Fondements de la clinique. Paris: Navarin. 
Bercherie P (2005) Histoire et positions des thérapeutiques en psychiatrie. Paris: L'Harmattan.

Binswanger L (2000) Sur la fuite des idées. Grenoble: Éditions Jérôme Million.

Briquet P (1859) Traité clinique et thérapeutique de l'hystérie, II. Paris: J.-B. Baillère et fils; republished by Théraplix in 'Analectes' collection in 1974.

Broussais F-J V (1828) De l'irritation et de la folie. Bruxelles: Librairie médicale et scientifique.

Charcot J-M (1971) L'hystérie. Textes choisis et présentés par E. Trillat. Paris: Privat.

De Waelhens A (1980) La Psychose, essai d'interprétation analytique et existentielle. Leuwen, Bruxelles: Nauwelaerts éditeur.

Dimitriadis Y (2018) Schizophrenia as a psychosomatic illness: an interdisciplinary approach between Lacanian psychoanalysis and neurosciences. Bulletin of Menninger Clinic 82(1):1-18.

Ehrenberg A (2004) Le sujet cérébral. Esprit (Nov.): 130-155.

Esquirol J-E (1998) Des Maladies mentales, tome I. Paris: Éditions Privat.

Ey H (1950) Avertissement. In: Bonnafé L et al. (eds) Le Problème de la psychogenèse des névroses et des psychoses. Paris: Desclée de Brouwer, 7.

Ey H (2006) Principes d'une conception organodynamiste en psychiatrie. Études psychiatriques, new edn, Vol. I. Perpignan: Crehey, 157-186; originally published in 1948.

Follin S (1993) Discours sur Paul Guiraud. L'Évolution psychiatrique 58 (4): 651-658.

Georget J-E (1999) De la folie, ed. J Postel. Paris: L'Harmattan; originally published in 1920.

Goldstein K (1983) La Structure de l'organisme. Paris: Gallimard.

Griesinger W (1865) La pathologie mentale du point de vue de l'école somatique allemande, précédé d'une introduction de Jules Falret. Annales médico-psychologiques 5(Jan., 4e série): $1-31$.

Grmek MD (1997) Les Legs de Claude Bernard. Paris: Fayard.

Guiraud P (1950) Psychiatrie générale. Paris: Le François.

Jeannerod M (1996) De la physiologie mentale. Histoire de relations entre biologie et physiologie. Paris: Odile Jacob.

Jung CG (2001) Psychologie de la démence précoce: essai [1907]. In: Psychogénèse des maladies mentales. Paris: Albin Michel, 13-187.

Lanteri-Laura G (1998) Essai sur les paradigmes de la psychiatrie moderne. Paris: Éditions du temps. 
Le Gauffey G (1992a) L'abandon de la théorie de la séduction chez Freud, 1ère partie. Littoral 34/35: 201-222.

Le Gauffey G (1992b) L'abandon de la théorie de la séduction chez Freud, 2ème partie. Littoral 36: 211-232.

Mayer P and Triadou P (1996) Leçons d'histoire de la pensée médicale. Paris: Odile Jacob. Minkowski E (1968) Le Temps vécu. Neuchâtel: Delachaux et Niestlé S.A.

Minkowski M (1935) Essai d'analyse et de synthèse biologiques des troubles organiques et fonctionnels en neurologie. L'Évolution psychiatrique 7(1): 3-35.

Oury J (1989) Création et schizophrénie. Paris: Gallilée.

Postel J (1997) Présentation. In: Kraepelin E, Leçons cliniques sur la démence précoce et la psychose maniaco-dépressive. Paris: L'Harmattan, 5-19.

Postel J (1999) Introduction. In: Georget J-E, De la folie, ed. J Postel. Paris: L’Harmattan, 722.

Postel J (2007) Eléments pour une histoire de la psychiatrie occidentale. Paris: L'Harmattan. Starobinski J (1999) Action et réaction. Paris: Seuil.

Vié J (1934) Comment concevoir actuellement l'organique et le fonctionnel en neuropsychiatrie. Hygiène mentale 29(3): 45-71.

Von Monakow C and Mourgue R (1928) Introduction biologique à l'étude de la neurologie et de la psychopathologie. Paris: Librairie Félix Alcan. 